\title{
Retrospective case series with one year follow-up after radial nerve palsy associated with humeral fractures
}

\author{
Nikolaus Wilhelm Lang ${ }^{1} \cdot$ Roman Christian Ostermann ${ }^{1}$ • Cathrin Arthold ${ }^{1}$. \\ Julian Joestl ${ }^{1}$ • Patrick Platzer ${ }^{1}$
}

Received: 6 January 2016 / Accepted: 27 March 2016/Published online: 14 April 2016

(C) The Author(s) 2016. This article is published with open access at Springerlink.com

\begin{abstract}
Purpose The purpose of this study was to assess recovery and clinical outcome in patients with primary or secondary radial nerve palsy following humeral shaft fracture.

Methods We retrospectively assessed 102 patients (45 female and 57 male) with humeral shaft fracture and concomitant radial nerve palsy, who were followed up for 12 months. Patients were divided into two groups with primary or secondary radial nerve palsy depending on the onset. Muscle function was measured according to Daniels classification and degree of nerve damage was assessed by the Sunderland classification.

Results The average time for onset of recovery after primary RNP was $10.5 \pm 3.31$ weeks, in the case of secondary RNP it was $8.9 \pm 7.98$ weeks $(\mathrm{p}<0.05)$. Full recovery or significant improvement was achieved with average of $26.7 \pm 8.86$ weeks and $23.9 \pm 6.04$ weeks respectively $(\mathrm{p}<0.05)$. Trauma mechanism and type of treatment had no significant influence on time of onset of recovery or time to full recovery $(\mathrm{p}<0.904)$. Conclusion Secondary RNP shows tendency for earlier recovery and is more commonly associated with ORIF.
\end{abstract}

Keywords Radial nerve palsy · ORIF · Intramedullary nail · Recovery

Nikolaus Wilhelm Lang

nikolaus.lang@meduniwien.ac.at

1 Department of Traumatology, Medical University of Vienna, Waehringer Guertel 18 - 20, Vienna A - 1090, Austria

\section{Introduction}

Humeral shaft fractures are often associated with radial nerve palsy, which represents the most common traumatic nerve injury [1-3]. The overall incidence of radial nerve palsy following humeral shaft fractures is about $2-18 \%$, in mean $12 \%$ [4, 5]. Due to different methods of fixation for humeral shaft fractures regarding closed or open fracture reduction, it is necessary to decide if early exploration in primary radial nerve palsy is indicated $[4,6]$. Thus open exploration facilitates fracture reduction and reduces damage by bony fragments and entrapment of the nerve $[4,7]$. Open or closed reduction of humeral shaft fractures is accompanied by resulting secondary radial nerve palsy in 6-12\% [8]. However, due to a high rate of spontaneous recovery, conservative treatment of radial nerve palsy and non operative fracture fixation have been postulated [6].

The purpose of this study was to assess recovery time and clinical outcome in patients with primary or secondary radial nerve palsy after humeral shaft fracture (at a European level I trauma centre.)

\section{Material and methods}

The study was approved by the local ethic committee and was performed in accordance to the Declaration of Helsinki. Written informed consent was obtained from all patients before enrolment (EK Nr. 2010/593).

\section{Study design and patient recruitment}

We performed a retrospective analysis of prospectively collected data for all patients treated with humeral shaft fractures and accompanying radial nerve palsy at this level I trauma centre. A sample of 615 patients who sustained a traumatic humeral 
shaft fracture and were treated at our department between 1994 and 2013, was sorted and their dataset was examined for completeness and accuracy. Patients with an incomplete dataset, pathologic or periprosthetic fractures as well as patients who received non surgical treatment or were younger than 18 years of age were excluded. According to this inclusion criteria a total of 102 patients with primary or secondary radial nerve palsy following surgical treatment of humeral shaft fracture resulted revealing an incidence of radial nerve palsies of $16.6 \%$ (primary $8.9 \%$ and secondary $7.7 \%$ ). A total of 45 women and 57 men with a median age of 46 years (range 18-87 years) were included in our series. The mean age of the male group was considerably lower (38.4 years), than that of the female group (56.2 years). Depending on the onset of radial nerve palsy patients were divided into two groups (A \& B). Patients with primary radial nerve palsy were included into study group A, whereas patients showing a deficit of radial nerve function following initial surgical treatment were considered as those with a secondary radial nerve lesion and entered study group B. The causes of injury are summarized in Table 1.

\section{Diagnosis and surgical management}

All humeral shaft fractures were classified according to the AO classification system. Soft tissue damage was determined according to the Gustilo and Anderson classification $[9,10]$.

Table 1 Demographic data

\begin{tabular}{lllll}
\hline & Overall & Primary & Secondary & P value \\
\hline Patients (n) & 102 & 55 & 47 & \\
Gender (n) & & & & \\
$\quad$ Female & 45 & 20 & 25 & n.s. \\
Male & 57 & 35 & 22 & n.s. \\
Age (years) & & & & \\
Female & 56.2 & 56.27 & 56.16 & n.s. \\
Males & 38.4 & 37.50 & 39.70 & n.s \\
Trauma mechanism & & & & \\
$\quad$ Sports injury & 11 & 5 & 6 & n.s \\
MVA & 28 & 19 & 9 & $<0.05$ \\
Fall $>3$ m & 14 & 8 & 6 & n.s \\
Fall $<1$ m & 42 & 20 & 22 & n.s \\
Hit on arm & 7 & 3 & 4 & n.s \\
High energy & 53 & 32 & 21 & n.s \\
Low energy & 49 & 23 & 26 & n.s \\
Treatment & & & & $<0.0$ \\
IN & 25 & 20 & 5 & n.s. \\
ORIF & 76 & 35 & 41 & $<0.05$ \\
Fix Ex & 1 & & 1 & \\
Onset of recovery & 9.6 & 10.5 & 8.7 & 22.7 \\
Total recovery & 24.9 & 26.7 & & $<05$ \\
\hline
\end{tabular}

*not significant
Fracture fixation methods included external fixation, open reduction with internal fixation (ORIF) and antegrade or retrograde interlocking intramedullary nailing (IN).

\section{Outcome assessment}

Clinical and radiographic examination was routinely performed three, six and twelve months after initial trauma to determine bone union. Nerve conduction studies (NCV) were routinely performed at two weeks following onset of radial nerve palsy and again after four months in case of delayed recovery. Functional assessment was routinely performed at all follow up visits. The grade of nerve damage was determined with Sunderland classification and muscle function was assessed by manual muscle test according to Daniels and Worthingham [11].

\section{Statistical analysis}

Quantitative data were compared between the two groups using two way ANOVA and Mann Whitney test U, qualitative data were compared using the $\mathrm{x}^{2}$-analysis. Statistical significance was set at $\alpha=0.05$. Multiple regression analysis with a $95 \%$ confidence interval was used to examine the independent associations of various demographic and injury related factors $\alpha=0.05$ was considered to determine the statistical significance of corresponding variables (age, sex, injury mechanisms, associated injuries, surgical techniques and clinical outcome).

\section{Results}

\section{Mechanism of injury and fracture classification}

A total of 53 patients (52\%) sustained a high energy trauma and 49 (48\%) patients sustained a low energy trauma leading to a humeral shaft fracture. In study group A, 32 patients $(58.2 \%)$ and in group B, 21 patients $(44.7 \%)$ sustained a high energy trauma (Table 1). High energy trauma was more frequently seen in male patients $(68.4 \%)(\mathrm{p}<0.05)$ whereas low energy trauma was more common in female patients $(68.8 \%)$ $(\mathrm{p}<0.05)$.

In regards to humeral shaft fractures associated with radial nerve lesion, the most common types involved A1 $(n=26)$ and B1 $(n=28)$ fractures. Furthermore, we observed 12 A2 fractures, ten A3 fracture, seven B2 fractures and another seven B3 sub-types. Complex fractures were seen in 15 patients, including five $\mathrm{C} 1$, seven $\mathrm{C} 2$ and three $\mathrm{C} 3$ sub-types (Table 2). There were nine open fractures, including two grade I, five grade II and two grade III fractures. Eight of the total nine open fractures showed primary radial nerve palsy. Three of these nine cases revealed a complete disruption of the radial nerve at surgical exploration Table 2. 
Table 2 Fracture type AO/OTA classification

\begin{tabular}{llll}
\hline & Overall & Primary & Secondary \\
\hline Patients (n) & 102 & 55 & 47 \\
Fracture type & & & \\
A1 & 26 & 16 & 10 \\
A2 & 11 & 5 & 6 \\
A3 & 10 & 7 & 3 \\
B1 & 27 & 15 & 12 \\
B2 & 7 & 3 & 4 \\
B3 & 6 & 3 & 3 \\
C1 & 5 & 2 & 3 \\
C2 & 7 & 3 & 4 \\
C3 & 3 & 1 & 2 \\
\hline
\end{tabular}

\section{Analysis of surgical management}

Surgical management was performed with a median delay of three days. Within group A, 35 patients were treated with ORIF. Twenty patients underwent treatment with interlocking intramedullary nails. In eight of those cases additional surgical exploration of the radial nerve was performed. In the remaining 12 patients, including A2 and A3 fractures, no further investigation of the nerve was performed. Treatment with IN was significantly more common among fracture type A $(p<0.05)$ compared to type B and C fractures. Three patients sustained a complete radial nerve transection, grade $\mathrm{V}$ lesion. Two of them presented with open deux etage fractures (12 C 2 ) and the third patient showed a complex multifragmentary fracture (12 C 3). One patient suffered concomitant lesions of the median, ulnar and musculocutaneous nerve where primary suture of the nerves was performed. In the other two cases the radial nerve had to be reconstructed with an autologous nerve graft of the N. cutaneous brachii posterior. Two further patients showed partial laceration of the radial nerve (grade IIIII lesion), which were treated by primary suture. In 17 patients the radial nerve showed signs of contusion, grade I-II lesion. In seven patients a bony fragment compromised the radial nerve, showing a grade I-II lesion. In eight patients the nerve was severed by traction or was walled up by connective tissue, resulting in a grade I-II lesion. In five patients the radial nerve was found to be macroscopically intact, resembling a grade I lesion.

Among the 47 patients in group B, 41 patients underwent surgical treatment with ORIF. Five patients were treated with IN. One patient developed a secondary radial nerve palsy following surgical treatment by an external fixator. During the surgical exploration a total of 21 patients showed no macroscopically lesions of the radial nerve, grade I lesion. In four patients the radial nerve was walled up by connective tissue, leading to a grade I-II lesion. Intraneural haematoma was found in five patients, suggesting a grade II lesion. In eight patients there was an entrapment of the nerve in the fracture gap (grade I-II lesion). Secondary radial nerve palsy was significantly $(\mathrm{p}<0.05)$ more common in patients undergoing ORIF.

Fracture type and trauma mechanism had no significant influence on the grade of nerve damage. However there was a tendency of type $\mathrm{C}$ and open fractures to be associated with more severe nerve damage.

Within the follow-up we observed a breakage of the plate or breakage of multiple screws four times. In seven patients treated with ORIF and in three patients treated with IN we observed delayed bone union, whereas we observed no influence on recovery of radial nerve palsy.

\section{Recovery and clinical outcome}

The mean time to onset of recovery of the observed primary radial nerve palsies was $10.5 \pm 3.31$ weeks. In 45 patients $(81.8 \%)$ full recovery (strength M5) was achieved afater $26.7 \pm 8.86$ weeks. In six patients $(11 \%)$ full recovery (strength M4) was achieved within 12 months. Four patients showed no signs of remission, resulting in a strength deficite M1-2.

Within group B the onset of secondary radial nerve palsy was noted with a mean delay of $8.9 \pm 7.98$ weeks following the initial trauma. There was a significant difference in time to onset of recovery between patients with primary and secondary radial nerve palsy $(\mathrm{p}<0.05)$. In 39 patients $(82.3 \%)$ full recovery (strength M5) was achieved in an average of and $23.9 \pm 6.04$ weeks, which represents a significant statistical difference in time to full recovery between group A and B ( $p$ $<0.05$ ). (Figs. 1 and 2). In five patients $(10.6 \%)$ full recovery or significant improvement (strength M4) was achieved within 12 months. Three patients showed no signs of remission (strength M1-2) as shown in Figs. 1 and 2.

Trauma mechanism and type of treatment had no significant influence on time to onset of recovery or time to full recovery $(p=0.904)$. However patients sustaining a type A fracture and secondary radial nerve palsy showed significantly faster recovery $(\mathrm{p}<0.05)$. Additionally, in 39 patients (38.2\%) repeated electromyograms (EMG) and nerve conduction studies (NCV) were performed due to prolonged time of recovery. Following hospital discharge, all patients underwent a special rehab protocol under guidance of a skilled nurse.

At final follow up, 84 patients $(82.4 \%)$ presented with satisfying clinical function concerning the affected arm and could manage activities of daily living without any difficulties. Another 11 patients $(10.7 \%)$ showed mild to moderate impairment of motor function of the affected arm. Only seven patients $(6.8 \%)$ suffered from severe functional impairment and required further surgery. 
Fig. 1 Time to onset of recovery (weeks) in primary and secondray radial nerve palsy

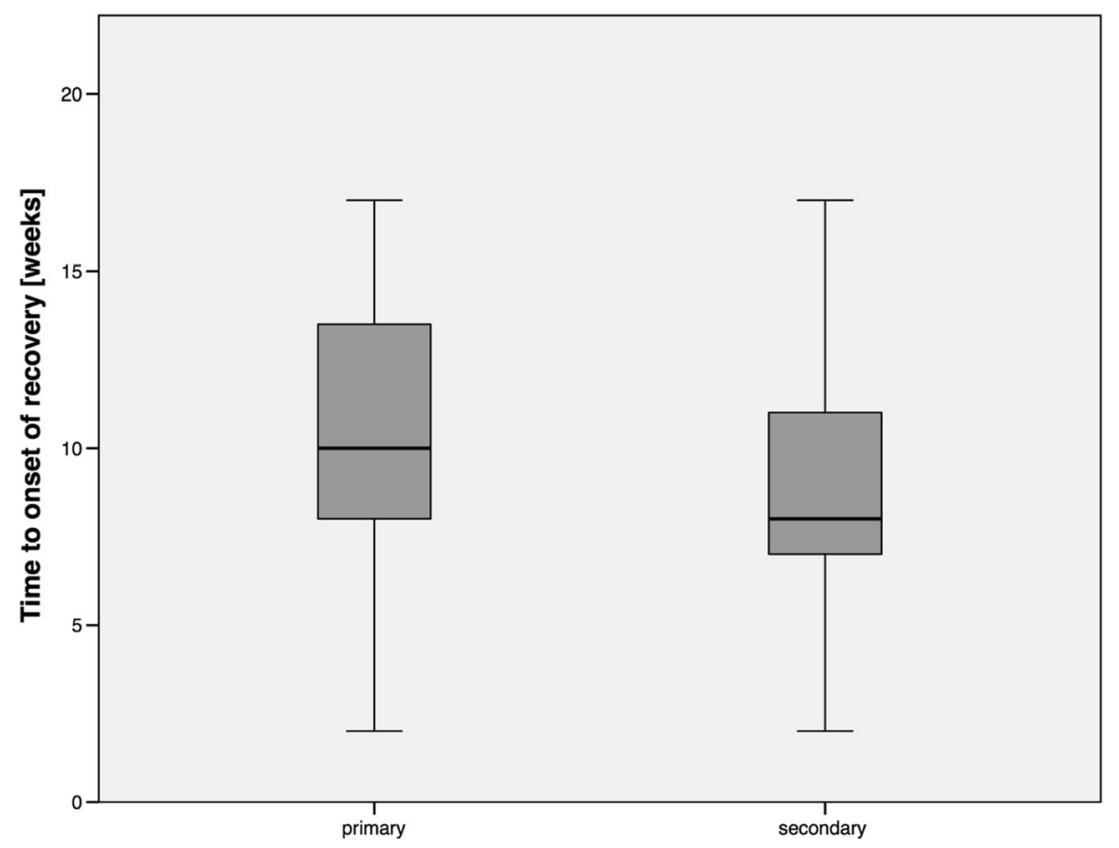

\section{Discussion}

Recovery of primary or secondary radial nerve palsy is influenced by various factors; therefore, we aimed to evaluate the affect of trauma mechanism, fracture type and surgical management on time to onset of recovery and time to full recovery in patients who suffered from primary or secondary radial nerve palsies.

About $50 \%$ of humeral shaft fractures are associated with high-energy trauma [12-14]. Studies by Venouziou et al. recently pointed out that patients sustaining high-energy trauma with humeral shaft fractures have a greater incidence and prolonged recovery of radial nerve palsy as well as inferior fracture healing [14]. The nerve is often found lacerated or entrapped between mobile bony fragments, in such cases early exploration is an absolute necessity $[1,13,14]$. In the case of low-energy trauma, radial nerve palsy is often caused by a nerve conduction block where the nerve is found macroscopically intact $[6,14,15]$. In recent years there has been a growing trend of cautious withholding until surgical treatment
Fig. 2 Time to full recovery or significant improvement (weeks) in patients with primary or secondary readial nerve palsy

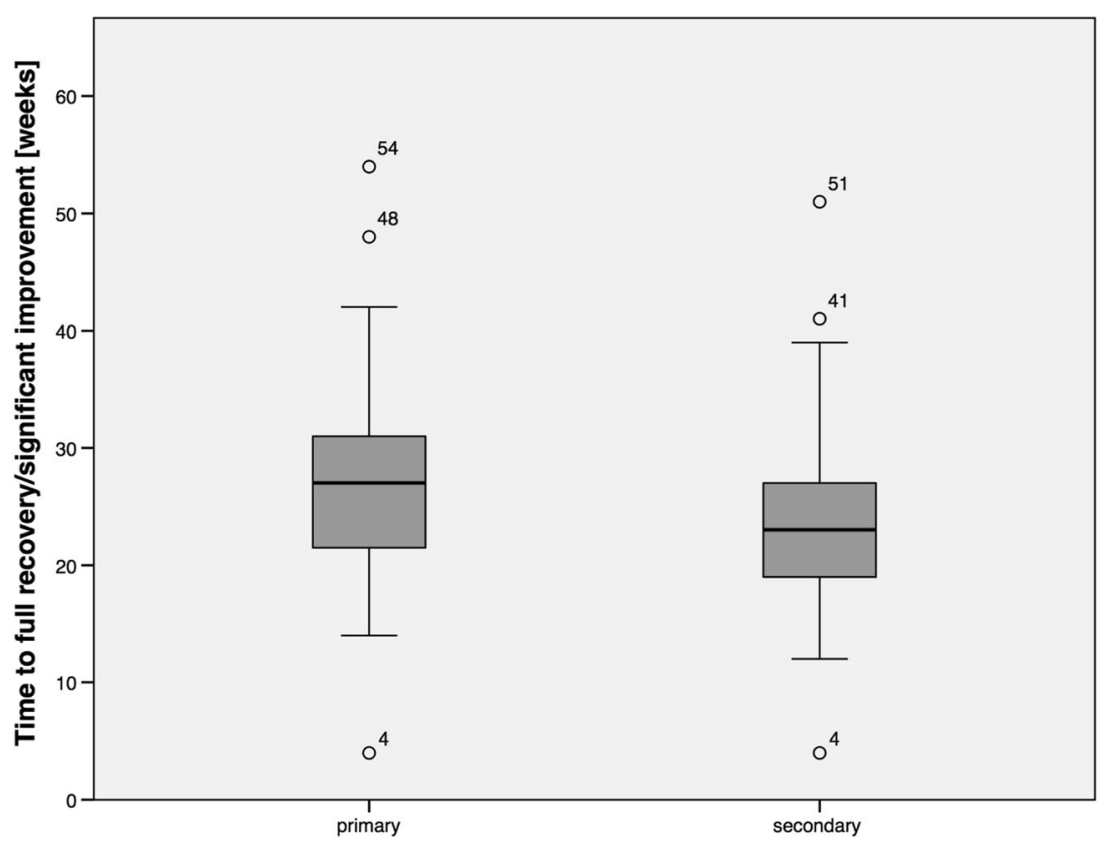


options are involved in patients sustaining low-energy trauma. Higher age and the higher incidence of comorbidities also contribute to the choice of less invasive treatment and to avoid further surgical intervention $[1,14,16]$. In our series high energy trauma was more frequently seen in young male patients $(68.4 \%)(\mathrm{p}<0.05)$ whereas low energy trauma was more common in female patients $(68.8 \%)(\mathrm{p}<0.05)$. Oppositional to current data, trauma mechanism had no significant influence on time to onset of recovery or time to full recovery $(\mathrm{p}=0.904)$ [14].

Both, ORIF and IN are well-established procedures with high rates of $85-93 \%$ of recovery following primary radial nerve palsy $[12,17-21]$. In the case of acute primary radial nerve palsy open reduction facilitates fracture treatment and enables simultaneous exploration of the radial nerve to determine the extent and the type of lesion [1, 7, 18]. It has been postulated that earlier surgical intervention with ORIF leads to earlier recovery of radial nerve palsy [21, 22]. Nevertheless, a relatively high incidence of secondary radial nerve palsy is associated with ORIF [19]. Still the question of correlation of bone union and recovery of radial nerve palsy remains unclear $[14,16]$. Allende et al. reported that revision surgery and additional neurolysis in case of nonunion following failed IN leads to satisfying recovery of radial nerve palsy [23] in certain cases. Compared to recent literature we could not find any coherence between type of treatment, bone union and recovery of radial nerve palsy $[14,21,23]$. Whereas secondary radial nerve palsy was significantly $(p<0.05)$ more common in patients undergoing ORIF. Therefore the decision of early exploration of the radial nerve should be in accordance with the choice of fracture treatment [2].

Time to recovery of primary and secondary radial nerve palsy depends on trauma mechanism, fracture type as well as the surgical management $[3,6,12,19,21,24]$. Shao et al. published that the rate of spontaneous nerve recovery after secondary radial palsy was similar to that of primary radial palsy with an average time of onset of 7.3 weeks ( 2 weeks6.6 months), the time of full recovery was reported with 6.1 months (3.4-12 months) [1]. In a recently published series Wang et al. found out that the average time of onset of clinical recovery in patients with secondary radial nerve palsy was 4.8 months (1-6 months), and the average time to full recovery was 8.5 months (3-12 months) [25]. In our series the time of spontaneous recovery in group A, with an incidence of $60 \%$ of patients sustaining high-energy trauma, was 10.5 weeks, whereas in group B the time of spontaneous recovery was 8.5 weeks respectively, $\mathrm{p}<0.05$. Time to total recovery was significantly shorter in patients with secondary radial nerve palsy $\mathrm{p}<0.05$. Furthermore type A fractures among patients in group B had a significantly shorter time of recovery $(p<0.05)$. Total recovery was observed in $82.4 \%$ of our patients. Apart from shorter time of recovery among secondary radial nerve palsy and type A fractures our findings seem to be consistent with those described in current literature $[1,6,12,21]$.

Without any doubt, there are several limitations to this study. We retrospectively evaluated a relatively small sample size. Besides, we analysed an inhomogeneous patient population regarding the trauma mechanism, fracture type, onset of radial nerve palsy and surgical procedure. As mentioned before, a possible selection bias during patient allocation to the treatment groups has to be pointed out.

\section{Conclusion}

Trauma mechanism had no significant influence on development of primary or secondary radial nerve palsy. Secondary radial nerve palsy is more commonly associated with open reduction and plate fixation; nevertheless it shows a high rate of spontaneous and significantly shorter recovery compared to primary radial nerve palsy.

Acknowledgments Open access funding provided by Medical University of Vienna.

\section{Compliance with ethical standards}

Conflict of interest The authors declare that they have no conflict of interest

Open Access This article is distributed under the terms of the Creative Commons Attribution 4.0 International License (http:// creativecommons.org/licenses/by/4.0/), which permits unrestricted use, distribution, and reproduction in any medium, provided you give appropriate credit to the original author(s) and the source, provide a link to the Creative Commons license, and indicate if changes were made.

\section{References}

1. Shao YC, Harwood P, Grotz MR, Limb D, Giannoudis PV (2005) Radial nerve palsy associated with fractures of the shaft of the humerus: a systematic review. J Bone Joint Surg (Br) 87(12): 1647-1652. doi:10.1302/0301-620X.87B12.16132

2. Elton SG, Rizzo M (2008) Management of radial nerve injury associated with humeral shaft fractures: an evidence-based approach. J Reconstr Microsurg 24(8):569-573. doi:10.1055/s-00281090623

3. Ljungquist KL, Martineau P, Allan C (2015) Radial nerve injuries. J Hand Surg [Am] 40(1):166-172. doi:10.1016/j.jhsa.2014.05.010

4. DeFranco MJ, Lawton JN (2006) Radial nerve injuries associated with humeral fractures. J Hand Surg [Am] 31(4):655-663. doi:10. 1016/j.jhsa.2006.02.013

5. Li Y, Ning G, Wu Q, Feng S (2013) Review of literature of radial nerve injuries associated with humeral fractures-an integrated management strategy. PLoS One 8(11), e78576. doi:10.1371/journal. pone. 0078576

6. Prodromo J, Goitz RJ (2013) Management of radial nerve palsy associated with humerus fracture. J Hand Surg [Am] 38(5):995998. doi:10.1016/j.jhsa.2013.02.003, quiz 998 
7. Korompilias AV, Lykissas MG, Kostas-Agnantis IP, Vekris MD, Soucacos PN, Beris AE (2013) Approach to radial nerve palsy caused by humerus shaft fracture: is primary exploration necessary? Injury 44(3):323-326. doi:10.1016/j.injury.2013.01.004

8. Pidhorz L (2015) Acute and chronic humeral shaft fractures in adults. Orthop Traumatol Surg Res 101(1S):S41-S49. doi:10. 1016/j.otsr.2014.07.034

9. Horn BD, Rettig ME (1993) Interobserver reliability in the Gustilo and Anderson classification of open fractures. J Orthop Trauma 7(4):357-360

10. Siebenrock KA, Gerber C (1992) Classification of fractures and problems in proximal humeral fractures. Orthopade 21(2):98-105

11. Hislop HJ, Montgomery J, Connolly BH, Daniels L (1995) Daniels and Worthingham's muscle testing: techniques of manual examination, 6th edn. Saunders, Philadelphia

12. Grass G, Kabir K, Ohse J, Rangger C, Besch L, Mathiak G (2011) Primary exploration of radial nerve is not required for radial nerve palsy while treating humerus shaft fractures with unreamed humerus nails (UHN). Open Orthop J 5:319-323. doi:10.2174/ 1874325001105010319

13. Ring D, Chin K, Jupiter JB (2004) Radial nerve palsy associated with high-energy humeral shaft fractures. J Hand Surg [Am] 29(1): 144-147

14. Venouziou AI, Dailiana ZH, Varitimidis SE, Hantes ME, Gougoulias NE, Malizos KN (2011) Radial nerve palsy associated with humeral shaft fracture. Is the energy of trauma a prognostic factor? Injury 42(11):1289-1293. doi:10.1016/j.injury.2011.01. 020

15. Ekholm R, Ponzer S, Tornkvist H, Adami J, Tidermark J (2008) Primary radial nerve palsy in patients with acute humeral shaft fractures. J Orthop Trauma 22(6):408-414. doi:10.1097/BOT. 0b013e318177eb06

16. Chen X, Liu T (2015) Does emergency surgical treatment allow good nerve recovery in humeral diaphyseal fractures associated with radial palsy? Int Orthop. doi:10.1007/s00264-015-3037-7
17. McCormack RG, Brien D, Buckley RE, McKee MD, Powell J, Schemitsch EH (2000) Fixation of fractures of the shaft of the humerus by dynamic compression plate or intramedullary nail. A prospective, randomised trial. J Bone Joint Surg (Br) 82(3):336339

18. Zhao JG, Wang J, Wang C, Kan SL (2015) Intramedullary nail versus plate fixation for humeral shaft fractures: a systematic review of overlapping meta-analyses. Medicine (Baltimore) 94(11), e599. doi:10.1097/MD.0000000000000599

19. Carroll EA, Schweppe M, Langfitt M, Miller AN, Halvorson JJ (2012) Management of humeral shaft fractures. J Am Acad Orthop Surg 20(7):423-433. doi:10.5435/JAAOS-20-07-423

20. Ma J, Xing D, Ma X, Gao F, Wei Q, Jia H, Feng R, Yu J, Wang J (2013) Intramedullary nail versus dynamic compression plate fixation in treating humeral shaft fractures: grading the evidence through a meta-analysis. PLoS One 8(12), e82075. doi:10.1371/ journal.pone. 0082075

21. Pailhe R, Mesquida V, Rubens-Duval B, Saragaglia D (2015) Plate osteosynthesis of humeral diaphyseal fractures associated with radial palsy: twenty cases. Int Orthop. doi:10.1007/s00264-015-2745-3

22. Bishop J, Ring D (2009) Management of radial nerve palsy associated with humeral shaft fracture: a decision analysis model. J Hand Surg [Am] 34(6):991-996. doi:10.1016/j.jhsa.2008. 12.029, e991

23. Allende C, Paz A, Altube G, Boccolini H, Malvarez A, Allende B (2014) Revision with plates of humeral nonunions secondary to failed intramedullary nailing. Int Orthop 38(4):899-903. doi:10. 1007/s00264-013-2180-2

24. Larsen LB, Barfred T (2000) Radial nerve palsy after simple fracture of the humerus. Scand J Plast Reconstr Surg Hand Surg 34(4): 363-366

25. Wang X, Zhang P, Zhou Y, Zhu C (2014) Secondary radial nerve palsy after internal fixation of humeral shaft fractures. Eur J Orthop Surg Traumatol 24(3):331-333. doi:10.1007/ s00590-013-1197-y 